\title{
Leg health, growth and carcass characteristics in growing-finishing pigs of two different genotypes reared on Swedish organic farms
}

\author{
A. Wallenbeck (D) - C. Eliasson • N. Lundeheim • \\ K. Nilsson
}

Received: 13 February 2019 / Accepted: 3 July 2019/Published online: 18 July 2019

C) The Author(s) 2019, corrected publication 2019

\begin{abstract}
Increased prevalence of joint abnormalities at slaughter among pigs from organically certified herds in Sweden has been reported. Most of these abnormalities are caused by osteochondrosis, which has a genetic background. Thus, we investigated whether changing the sire breed from the commonly used Hampshire to the commercially available sire breed Duroc affected joint health and growth rate. We studied 766 commercially reared growing-finishing pigs from insemination of the mother sow until slaughter. The pigs were raised at four commercial organic farms (integrated or externally integrated, and had 40-160 sows in production) and slaughtered at one slaughter plant. We found no significant difference between the offspring of the two sire breeds regarding back conformation, leg conformation, swollen joints, locomotion or lameness at 13 or 24 weeks of age, or regarding joint abnormalities at slaughter. This indicates that clinical leg health will not be improved by changing sire breed. However, the Hampshire-sired pigs had higher daily growth rate $(P<0.008)$, allowing earlier slaughter.
\end{abstract}

A. Wallenbeck · C. Eliasson · N. Lundeheim · K. Nilsson Department of Animal Breeding and Genetics, Swedish University of Agricultural Sciences, Ultuna, Sweden

A. Wallenbeck $(\bowtie)$

Department of Animal Breeding and Genetics, Sveriges lantbruksuniversitet, Box 7023, 75007 Uppsala, Sweden e-mail: anna.wallenbeck@slu.se

\section{A. Wallenbeck}

Department of Animal Environment and Health, Swedish University of Agricultural Sciences, Ultuna, Sweden
Keywords Breed - Outdoor production - Growth rate Leg health $\cdot$ Organic production $\cdot$ Pasture $\cdot$ Pig

\section{Introduction}

Organic pig production is characterised by large space allowance, outdoor access, roughage allowance, diets based on local feedstuffs and long nursing periods. Pigs from organically certified herds (KRAV 2011) have a higher prevalence of joint abnormalities at slaughter than conventionally reared pigs according to previous research (Hansson et al. 2000; Heldmer et al. 2006; Heldmer and Lundeheim 2010). This is probably caused by larger space allowance, allowing more exercise and higher pressure on immature joints (Heldmer 2009), and access to pasture, where pigs risk slipping and splaying themselves (Etterlin et al. 2014). The most common reason for joint rejection at slaughter is osteochondrosis, caused by abnormal changes in the bone formation in the joints due to necrosis in the vessels (Gångare 2009; Heldmer 2009). Osteochondrosis is a heritable condition associated with overall leg weakness (Lundeheim 1987; Stern et al. 1995; Ytrehus et al. 2004). Poor leg health causes pain and distress in the pigs, and joint remarks at slaughter often lead to reduce payment as parts of the carcasses often are discarded. Furthermore, joint abnormalities at slaughter are associated with low growth (Lundeheim 2010), which may further reduce income for producers.

A few previous studies have investigated the effect of breed on leg health in extensively reared pigs. 
Lundeheim et al. (1995) found that the prevalence of osteochondrosis is lower in finishing pigs sired by Duroc boars than that by Yorkshire boars (Yorkshire $x$ Landrace hybrid dams), but with no difference between finishing pigs sired by Hampshire compared with Yorkshire. Leufvén $(2004)$ found that Yorkshire $\times$ Duroc gilts had fewer deviations from the desired conformation than Yorkshire $\times$ Landrace gilts.

Organic pig producers in Sweden use the same genetic material as conventional producers, i.e. breeds selected for high production performance in conventional indoor environments. Swedish organic producers typically use a three-way cross: a Landrace $\times$ Yorkshire dam bred with a Hampshire sire. Besides the Hampshire sire breed, semen from the Duroc breed is available on the market for Swedish pig producers. There are few studies on differences in performance between these breeds under commercial production conditions (Mattson et al. 2005), and we have not found any studies on their performance in Swedish organic pig production environments. Besides potential differences in leg health, there could also be differences in growth performance when rearing offspring under extensive conditions in organically certified herds. If a change in sire breed were to improve leg health, this could lead to increased welfare for the pigs and reduced costs for organic pig producers in Sweden. However, the economic outcome for producers would also depend on growth performance of the respective breed combinations.

The overall aim of this study was to investigate the effects of sire breed on clinical leg health, growth and carcass characteristics in growing-finishing pigs reared in organic production environments. The specific objective was to compare offspring of Hampshire and Duroc boars in terms of differences in clinical lameness, locomotion, swollen joints, leg and back conformation during early and late rearing, growth, slaughter weight and incidence of leg joint rejections at slaughter.

\section{Material and methods}

All procedures in the study were approved by the National Ethics Committee for Animal Experiments (C186/11, Uppsala, Sweden), and all pig owners gave written approval for their animals to be included in the study.
Animals and housing

The study included 1256 live-born pigs from 97 litters born in four commercial organically certified herds (according to the regulations of the Swedish certification organisation KRAV) located in central Sweden (latitude $59^{\circ}-61^{\circ}$ ). The four herds were either integrated or externally integrated and had 40-160 sows in production. The dams were Swedish Yorkshire $\times$ Norwegian Landrace hybrids. In each production batch in each herd, half the sows were inseminated with a Duroc sire (22 different sires used) and half with a Hampshire sire (36 different sires used). All semen used was from individual boars with known identity and all sows were inseminated with the same boar during one oestrous, i.e. pedigree was known for all individual growingfinishing pigs included in the study. Insemination started in September 2011 and the last pigs in the study were slaughtered in March 2013. In total, 490 animals were lost before slaughter, mainly due to lost ear-tags but also due to mortality and culling. In some cases, pigs were sent to slaughter without the knowledge of the researches and were thus excluded from the study. The remaining 766 growing-finishing pigs (388 Hampshiresired and 378 Duroc-sired) were scored for clinical leg health and conformation. Of these pigs, 645 had individual carcass information recorded at the slaughterhouse (333 Hampshire-sired and 312 Duroc-sired).

All sows farrowed indoors in conventional individual loose-house farrowing pens, where the sow and her piglets were kept during the first 2 weeks after farrowing. At week 2 or 3 after farrowing, sows and their piglets were moved to group housing, with a total of 4-10 sows and their piglets, in either indoor deepstraw pens (non-growing season, October-April) or pasture (growing season, May-September). The pigs in deep-straw pens had outdoor access on concrete floor, while those on pasture had access to either huts or a house with deep-straw bedding. All animals were fed diets including roughage and based on locally produced feedstuffs, according to KRAV organic certification regulations (KRAV 2011). Cross-fostering between sows was performed according to standard routines in the herds during the first week after farrowing and birth litter identity was recorded.

Piglets were weaned at 6-7 weeks of age, by removal of the sow from the pen or pasture. Piglets stayed in the same groups and housing system as during the nursing period until slaughter. Pigs from all herds were 
slaughtered at the same slaughterhouse in south-west Sweden when they reached approximately $120 \mathrm{~kg}$ live weight, at approximately 6 months of age.

Before 2 weeks of age, all pigs were identity-marked with electronic ear-tags (EID) (Combi E®) and birth litter (including pedigree) was recorded. When cross-fostering was applied, this was recorded. To identify the individual pig on the farm and the carcass at the slaughterhouse, a hand-scanner (HHR 3000 Pro V2 HandHeld Reader, approved for reading ISO 11784/11785 transponders (BioControl, Rakkestad, Norway) was used to read the identification number on the ear-tag. Pigs were also tattooed with individual numbers 2 weeks prior to slaughter, to ensure identification at slaughter if ear-tags were lost.

Data collection

Pigs were individually assessed for clinical leg health on two occasions: at $30 \mathrm{~kg}$, which corresponded to approximately 13 weeks of age ( $90 \pm 19.5$ days), and at $>100 \mathrm{~kg}$ live weight which corresponded to approximately 24 weeks of age $(170 \pm 17.4$ days). The same trained research technician performed all assessments for all pigs and on both occasions. Scoring was performed according to a protocol developed and used by the breeding organisation Nordic Genetics for evaluation of conformation and leg health (Fig. 1). It includes locomotion (from score 1 (winding movements where the pig moves from side to side) to score 5 (stiff movements), with score 3 indicating optimum normal movement), lameness (from score 0 (no lameness) to score 3 (very lame)), swollen joints (at least one swollen joint: yes or no) and back and leg conformation (score 1 to 3, with score 2 indicating optimum normal conformation). Assessments were performed in a $5-10-\mathrm{m}^{2}$ area on a dry, solid, flat floor, either in the house or on a transport pen in the pasture. All pigs were kept individually in the assessment area when scored.

Date of birth, date of each leg assessment and date at slaughter were recorded for each individual pig.

Individual records of carcass weight, carcass leanness (percentage meat in the carcass determined with the Hennessy Grading Probe (Hennessy Grading Systems, Auckland, New Zealand); Sather et al. 1991) and leg joint status in veterinary inspections were collected at slaughter. A research technician was present at slaughter each time pigs from the study were slaughtered, to collect data and link pig identity in ear-tag/tattoo and slaughter line identity. Growth was estimated as slaughter weight divided by age at slaughter (in days) and lean meat growth was estimated as carcass growth multiplied by percentage of meat in the carcass.

Statistical analyses

Statistical analyses were performed using Statistical Analysis Systems (SAS version 9.4, SAS Institute Inc., Cary, NC). Descriptive statistics were derived using PROC FREQ and PROC MEANS. Leg health assessment scores for locomotion, lameness, swollen joint and back and leg conformation were transformed into binomial variables (normal (0) or not normal (1)) (binomial distribution and logit link) before the statistical analyses.

Differences between sire breeds (Hampshire, Duroc) and between pig ages (13, 24 weeks) during clinical leg health assessment of locomotion, lameness, swollen joint and back and leg conformation were analysed with generalised linear models using PROC GLIMMIX (binomial distribution and logit link) using MODEL 1. Differences between sire breeds in slaughter weight and carcass lean meat percentage were analysed with a general linear model using MODEL 2 and differences in weight gain from birth to slaughter and lean meat growth using MODEL 3, using PROC MIXED in both cases:

MODEL 1: $y$ = sire breed + gender + herd + age at observation + birth sow + pig id $+e$

MODEL 2: $\quad y=$ sire breed + gender + herd + slaughter age + sire breed $\times$ gender + sire breed $\times$ herd + gender $\times$ herd + birth sow $+e$

MODEL 3: $y=$ sire breed + gender + herd + sire breed $\times$ gender + sire breed $\times$ herd + gender $\times$ herd + birth sow $+e$

where in all models, $y$ is the dependent variable and $e$ is the residual error. Sire breed (Hampshire or Duroc), gender (female or castrate), herd (A, B, C or D) and age at observation (13 or 24 weeks) were included as fixed effects; slaughter age was included as a continuous covariate and dam (nested within sire breed and herd) and individual pig ID (nested within sire breed, gender, herd and dam) was included as random effects. No interactions were included in model 1 as the model did not converge when these were included.

Residuals of all continuous (not binomially distributed) dependent variables were examined for normal distribution using PROC UNIVARIATE considering Shapiro-Wilks test and a normal probability plot. All 


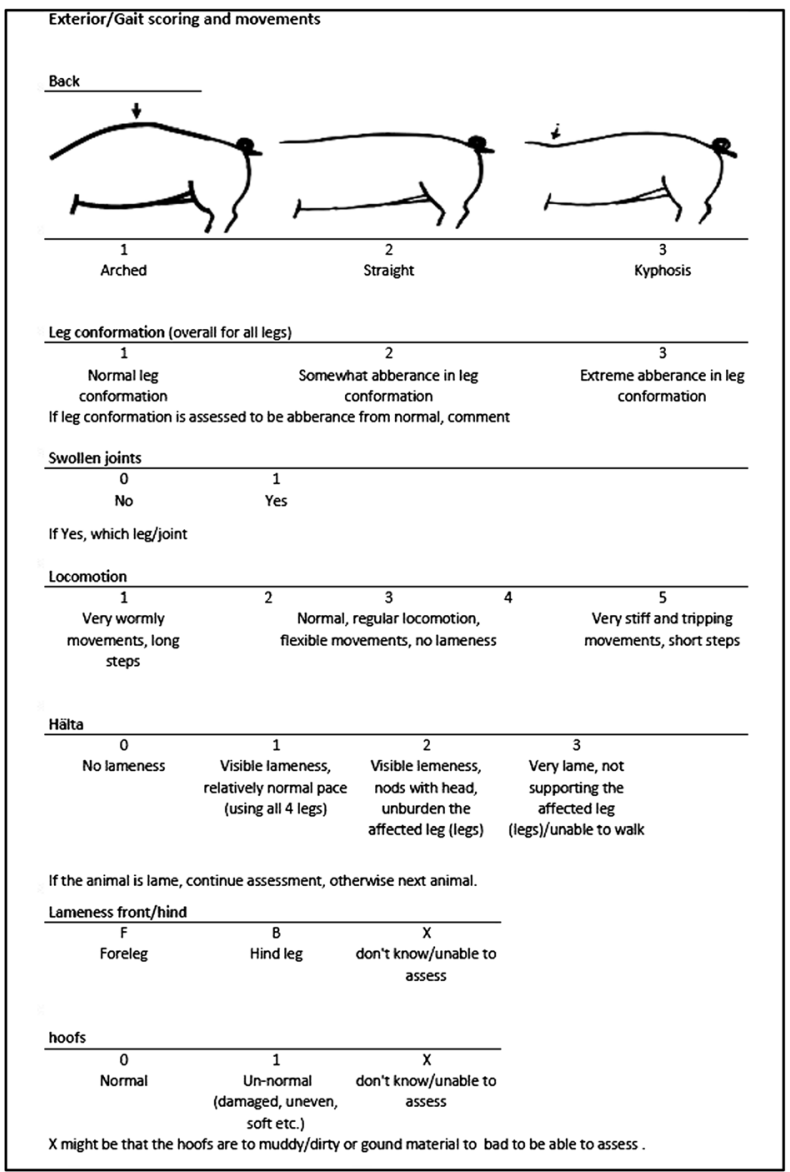

Leg conformation

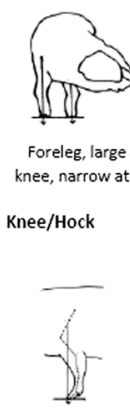

Sabre shaped foreleg
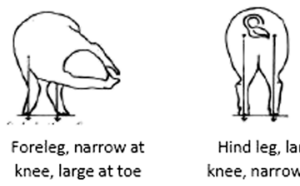

Hind leg, large at knee, narrow at toe

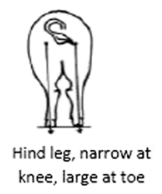

Vertebras

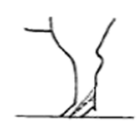

Soft, weak legs
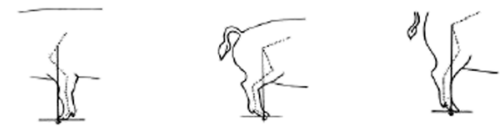

Knock-kneed foreleg

Hooked hind leg

Straight hind leg

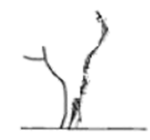

Stiff, straight legs

Klövar

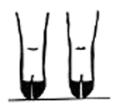

Normal hoofs
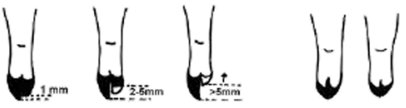

Exemple on hoofs not normal; uneven, small, tight etc.

Fig. 1 Protocol for exterior and gait assessment. Modified from the protocol developed and used by the breeding organisation Nordic Genetics for evaluation of conformation and leg health

residual variables were found to be normally or approximately normally distributed.

The effect of season was considered and indirectly included in the effect of dam, as no sows had more than $1 \mathrm{~L}$ in this study. Interactions between fixed effects were tested and found not to be significant, and were thus not included in the final models. Results are presented as least square means (LSM) and standard error (SE) unless otherwise stated.

\section{Results}

Sire breed did not affect any of the clinical leg health indicators recorded in this study (Table 1). The proportion of pigs with joint damage at slaughter was low for both sire breeds and did not differ between pigs with a Hampshire and Duroc sire $(1.3 \%$ of slaughtered pigs for both sire breeds).
Table 1 Effect of sire breed (Hampshire or Duroc, averages of weeks 13 and 24) on clinical leg health in pigs reared in commercial organically certified herds. Least square means \pm standard error. $N$, number of observations

\begin{tabular}{llll}
\hline $\begin{array}{l}\text { Leg health assessment (\% of } \\
\text { pigs scored non-normal) }\end{array}$ & $\begin{array}{l}\text { Hampshire sire } \\
N=683\end{array}$ & $\begin{array}{l}\text { Duroc sire } \\
N=648\end{array}$ & $P$ \\
\hline Locomotion & $17.2 \pm 1.74$ & $16.5 \pm 2.23$ & 0.821 \\
Lameness & $12.0 \pm 1.74$ & $11.7 \pm 1.65$ & 0.868 \\
Swollen joint & $3.7 \pm 0.96$ & $2.6 \pm 0.71$ & 0.204 \\
Back conformation & $9.2 \pm 1.82$ & $13.5 \pm 2.28$ & 0.103 \\
Leg conformation & $11.6 \pm 1.86$ & $13.8 \pm 2.03$ & 0.347 \\
\hline
\end{tabular}


The proportion of pigs with non-normal scores increased over time for locomotion, lameness, swollen joints and leg conformation $(P<0.001$ for all traits) while the proportion of pigs scoring non-normal for back conformation decreased $(P<0.001)$ (Table 2$)$.

A higher proportion of males had swollen joints (4.5 \pm 1.07 versus $2.1 \pm 0.61 \%$ for females, $P=0.009$ ) and also a higher proportion of non-normal leg conformation scores $(15.3 \pm 2.07$ versus $10.5 \pm 1.59 \%, P=0.010)$ compared with females. Gender did not have a significant effect on any of the other clinical leg health traits assessed.

Herd influenced proportion of pigs with nonnormal scores for locomotion $(P=0.017)$, swollen joints $(P=0.009)$ and leg conformation $(P=0.001)$, but there was no clear pattern indicating that pigs in specific herds generally had better or worse overall clinical leg health.

Pigs with a Hampshire sire showed higher daily growth, lean meat growth and carcass weight, and tended to have a higher meat percentage in the carcass than Duroc-sired pigs (Table 3). There were no significant differences between genders in carcass weight at slaughter, but surgically castrated male pigs had a leaner carcass $(55.9 \pm 0.26$ vs. $56.9 \pm 0.27 \%, \mathrm{LSM} \pm \mathrm{SE})$ and grew faster than female pigs $(463 \pm 5.3$ vs. $452 \pm 5.5 \mathrm{~g}$ per day, $\mathrm{LSM} \pm \mathrm{SE})(P<0.05)$. Herd had a significant effect on carcass weight at slaughter, carcass leanness and growth $(P<0.05)$ origin from one herd having pigs with lower average carcass weight and growth than the other three herds, and another herd having pigs with a leaner carcass than the other three herds. The interaction between breed and herd was significant for carcass weight at slaughter and growth due to a larger difference between breeds in one of the herds. The interaction between breed and sex was significant for carcass leanness and gender due to a larger difference between genders in the Duroc compared with the Hampshire breed.
Table 3 Carcass characteristics and growth performance in pigs reared in commercial organically certified herds. Least square means \pm standard error. $N$, number of pigs

\begin{tabular}{llll}
\hline Performance & $\begin{array}{l}\text { Hampshire sire } \\
N=314\end{array}$ & $\begin{array}{l}\text { Duroc sire } \\
N=300\end{array}$ \\
& $P$ & \\
\hline Carcass weight $(\mathrm{kg})$ & $93.8 \pm 0.99$ & $89.1 \pm 0.74$ & $<0.001$ \\
$\begin{array}{l}\text { Meat percentage in } \\
\quad \text { carcass (\%) }\end{array}$ & $56.8 \pm 0.38$ & $55.9 \pm 0.28$ & 0.055 \\
Growth (g/day) & $478 \pm 7.8$ & $438 \pm 5.7$ & $<0.001$ \\
Lean meat growth (g/day) & $272 \pm 4.8$ & $245 \pm 3.5$ & $<0.001$ \\
\hline
\end{tabular}

\section{Discussion}

In this study, we found no significant effect of sire breed on clinical leg health. Although leg health has a genetic background (Lundeheim 1987; Stern et al. 1995), there seemed to be no genetic advantage for either of the breeds assessed in this study regarding clinical leg health in organic production environments. The pigs in this study had a hybrid sow crossed between Yorkshire and Landrace and a sire of Duroc or Hampshire breed. Thus, the comparison was only between sire breed and half of the genetic influence come from the mother. There might be differences between pure-bred Duroc and Hampshire pig, which might have been diluted by the maternal influence. However, the breed crosses assessed in this study are the breed crosses used in commercial organic production in Sweden; thus, the results are relevant for that target group. Accordingly, sire breed did not have a significant effect on the proportion of pigs with joint damage at slaughter. The total incidence of joint rejections at slaughter was very low in this study (1.3\%). However, Etterlin et al. (2015) have shown that the association between joint rejections at slaughter and gait scoring in pigs reared in organic production environments can be weak, and thus, joint rejection incidence at slaughter may be a poor indicator of clinical leg health. Thus, to assess pig welfare, it is
Table 2 Effect of age on clinical leg health and conformation in pigs reared in commercial organically certified herds. Least square means \pm standard error. $N$, number of observations

\begin{tabular}{llll}
\hline $\begin{array}{l}\text { Leg health (\% of pigs scored } \\
\text { non-normal) }\end{array}$ & $\begin{array}{l}13 \text { weeks } \\
N=641\end{array}$ & $\begin{array}{l}24 \text { weeks } \\
N=690\end{array}$ & $P$ \\
\hline Locomotion & $7.5 \pm 1.25$ & $33.7 \pm 2.93$ & $<0.001$ \\
Lameness & $5.1 \pm 0.98$ & $25.2 \pm 2.32$ & $<0.001$ \\
Swollen joint & $1.1 \pm 0.42$ & $8.1 \pm 1.38$ & $<0.001$ \\
Back conformation & $17.0 \pm 2.38$ & $7.2 \pm 1.31$ & $<0.001$ \\
Leg conformation & $4.5 \pm 0.93$ & $31.1 \pm 2.80$ & $<0.001$ \\
\hline
\end{tabular}


important to investigate pig lameness during rearing rather than scanning the occurrence of osteochondrosis in carcasses.

The proportion of pigs with non-normal locomotion, lameness, leg conformation and swollen joints was much higher in week 24 than that in week 13, increasing with 7 to $25 \%$. However, the most severely lame pigs were culled during the rearing period and not included in the second leg health assessment. These findings indicate that pig leg health is challenged during rearing in environments with large space allowances and outdoor access and point at the importance of preventing and monitoring leg health in such production systems. The high percentage of pigs with locomotion problems (33.7\%) and lameness (25.2\%) at 24 weeks of age is unacceptable and more research on alternative breeds and the influence of the extensive environment organic pigs held is needed. The proportion of pigs with nonnormal back conformation decreased over time. This might be due to some pigs 'growing into their backs', as one of the producers in the study put it, but it is more likely that it was due to culling of unhealthy pigs, thus reducing the number of pigs with non-normal backs. Back conformation is included in the protocol for breeding evaluation and was consequently included in this study. However, the results point towards a lack of relationship between back conformation and pig locomotion and lameness.

Slaughter weight and carcass meat percentage did not differ significantly between offspring of the two sire breeds, although there was a tendency for Hampshire offspring to be heavier than Duroc offspring at slaughter. This lack of clear difference was expected, as producers are very careful to send pigs to slaughter at a weight within the best-paid range. However, the age at which the pigs reached the best-paid slaughter weight in these organic herds was lower for Hampshire offspring than that for Duroc offspring, as indicated by higher growth rates. This contradicts findings by Mattson et al. (2005) that Duroc-sired pigs reared in Swedish herds have higher daily weight gain and can be slaughtered at a lower age than Hampshiresired pigs. However, in the study by Mattson et al. (2005), the pigs were reared in conventional, and not organically certified, herds. This discrepancy between the two studies might indicate genotype-environment interactions (Wallenbeck et al. 2009).

Of the 1256 live-born piglets with known pedigree, $60 \%$ were identified and individually scored for clinical leg health during the rearing period and $51 \%$ were successfully identified at the slaughterhouse and had individual slaughter records. It can be assumed that $20-25 \%$ of the live-born piglets died during the first week after farrowing and that some additional mortality occurred later in the rearing period, which increases the percentage of surviving pigs identified at leg assessment and at slaughter. This shows that large-scale trials using individual records on large numbers of individual pigs in extensive production environments, such as organic production, are possible.

In conclusion, there were no differences in important clinical leg health parameters between pigs sired by Hampshire and Duroc and reared in organically sired herds. Thus, there is no evidence that leg health in Swedish commercial organic herds can be improved by changing sire breed. However, organic producers may decide to choose Hampshire sires, based on the higher growth rate we found in Hampshire offspring reared in organic herds.

Acknowledgements The authors gratefully acknowledge the pig producers for their work efforts and contributions to the study, and SLU Ekoforsk for funding the study.

Funding Information Open access funding provided by Swedish University of Agricultural Sciences.

Open Access This article is distributed under the terms of the Creative Commons Attribution 4.0 International License (http:// creativecommons.org/licenses/by/4.0/), which permits unrestricted use, distribution, and reproduction in any medium, provided you give appropriate credit to the original author(s) and the source, provide a link to the Creative Commons license, and indicate if changes were made.

\section{References}

Etterlin PE, Ytrehus B, Lundeheim N, Heldmer E, Österberg J, Ekman S (2014) Effects of free-range and confined housing on joint health in a herd of fattening pigs. BMC Vet Res 10: 208

Etterlin P, Morrison D, Österberg J, Ytrehus B, Heldmer E, Ekman $\mathrm{S}$ (2015) Osteochondrosis, but not lameness, is more frequent among free-range pigs than confined herd-mates. Acta Vet Scand 58:63

Gångare A (2009) KRAV-grisar har fler ledanmärkningar än konventionellt uppfödda grisar. Swedish University of Agricultural Sciences. Department of Biomedical Sciences and Veterinary Public Health. Master's thesis 2009:41

Hansson I, Hamilton C, Ekman T, Forslund K (2000) Carcass quality in certified organic production compared with 
conventional livestock production. J Vet Med B Infect Dis Vet Public Health 47:11-120

Heldmer E (2009) Varför har ekologiska grisar mer ledanmärkningar vid slakt än konventionellt uppfödda grisar? Report Swedish Board of Agriculture Project no 251135/07

Heldmer E, Lundeheim N (2010) Gross lesions at slaughter among organic pigs in Sweden. Proceedings of 21st International Pig Veterinary Society (IPVS) Congress, Vancouver

Heldmer E, Lundeheim L, Robertsson JÅ (2006) Gross lesions at slaughter in ecological pigs. Svensk Vereinärtidning 13:13-19

KRAV (2011) Regler för KRAV-godkänd produktion. www.krav.se. Accessed 11 Dec 2012

Leufvén S (2004) Säsongsanpassad smågrisproduktion utomhus. Swedish University of Agricultural Sciences. Department of Animal Breeding and Genetics. Master's thesis 2004:264

Lundeheim N (1987) Genetic analysis of osteochondrosis and leg weakness in the Swedish pig progeny testing scheme. Acta Agric Scand 37:159-173

Lundeheim N (2010) Besiktningsfyndens inverkan på slaktkropparna. Djurhälsonytt 5

Lundeheim N, Nyström P-E, Andersson K (1995) Outdoor vs indoor raising of growing-finishing pigs. Does a genotype*environment interaction exist? Proceedings of 46th Annual Meeting of the European Association for Animal Production, Prague, Czech Republic

Mattson B, Lundeheim N, Andersson K (2005) Hampshire (homozygot bärare av RN-genen, quality genetics) eller Duroc (DanAvl) som faderras. Praktiskt Inriktade Grisförsök 35

SatherAP, Jones SDM, Tong AKW, Murray AC (1991) Halothane genotype by weight interactions on pig meat quality. Can J Anim Sci 71(3):645-658

Stern S, Lundeheim N, Johansson K, Andersson K (1995) Osteochondrosis and leg weakness in pigs selected for lean tissue-growth rate. Livest Prod Sci 44:45-52

Wallenbeck A, Rydhmer L, Lundeheim N (2009) GxE interactions for growth and carcass leanness: re-ranking of boars in organic and conventional production. Livest Sci 123:154-160

Ytrehus B, Grindflek E, Teige J, Studsjøen E, Grøndalen T, Carlson CS, Ekman S (2004) The effect of parentage on the prevalence, severity and location of lesions of osteochondrosis in swine. J Vet Med A Physiol Pathol Clin Med 51:188-195

Publisher's note Springer Nature remains neutral with regard to jurisdictional claims in published maps and institutional affiliations. 